Artigo

DOI| 10.21680/1981-1802.2020v58n57ID20329

\title{
A formação de pesquisadores no espaço grupal
}

\author{
Denize da Silveira Foletto \\ Silvia Maria de Aguiar Isaia \\ Universidade Federal de Santa Maria (Brasil)
}

\section{Resumo}

Neste artigo, tem-se como objetivo compartilhar os resultados de uma pesquisa em que se procurou identificar, interpretar e compreender a dinâmica constitutiva do Grupo de Análise Narrativa Discursiva (GAND), para a elaboração de uma Análise Narrativa Discursiva Grupal (ANDG). Trata-se de uma pesquisa qualitativa, com apoio referencial da Teoria da Ação Comunicativa, de Habermas (2012), e que utilizou, como procedimento de interpretação, a abordagem hermenêutico-reconstrutiva. $\bigcirc$ corpus da pesquisa incluiu a transcrição das quinze reuniões do GAND, entrevistas semiestruturadas com os membros e o diário de campo da pesquisadora. Como resultado, a dinâmica constitutiva do GAND decorreu do esforço de construção de uma ANDG, gerando formação de pesquisadores, atravessada por interações intersubjetivas entre as integrantes. Assim, a expectativa é que este trabalho sirva de incentivo para outras experiências dessa natureza, tendo em vista contribuir com a formação de um pesquisador multiplicador e independente, que saiba dialogar com o mundo da vida.

Palavras-chave: Grupo de Análise Narrativa Discursiva. Formação de pesquisadores. Análise narrativa discursiva grupal. Constituição de grupo.

\section{The researchers' formation in group work}

\section{Abstract}

In this article, we main to share the results of a research in which we sought to identify, interpret and understand the constitutive dynamics of the Discursive Narrative Analysis Group (GAND), for the elaboration of a Group Discursive Narrative Analysis (ANDG). It is a qualitative research, with support from the Theory of Communicative Action by Habermas (2012), which used, as an interpretation procedure, the hermeneutic-reconstructive approach. The research corpus includes a transcript of the fifteen GAND meetings, semi-structured interviews with members and the researcher's field diary. As a result, the constitutive dynamics of the GAND stemmed from the effort to build an ANDG, in order to generate researchers' formation, crossed by intersubjective interactions among the members. Thus, the expectation is that this work will serve as an incentive for other experiences of this nature and to contribute to the education of a multiplying and independent researcher, who knows how to dialogue with the world of life.

Keywords: Discursive Narrative Analysis Group. Researchers' formation. Group discursive narrative analysis. Group constitution. 
A formação de pesquisadores no espaço grupal

\section{La formación de investigadores en el espacio grupal}

\section{Resumen}

Este artículo tiene como objetivo compartir los resultados de una investigación en la que se buscó identificar, interpretar y comprender la dinámica constitutiva del Grupo de Análisis Narrativo Discursivo (GAND), para la elaboración de una Análisis Narrativa Discursivo Grupal (ANDG). Es una investigación cualitativa, con apoyo referencial de la Teoría de la Acción Comunicativa, de Habermas (2012), y que utilizó, como procedimiento de interpretación, el abordaje hermenéutico-reconstructivo. El corpus de investigación incluyó la transcripción de las quince reuniones de GAND, entrevistas semiestructuradas con los miembros y el diario de campo de la investigadora. Como resultado, la dinámica constitutiva de GAND ha derivado de construcción de una ANDG, generando formación de investigadores, atravesada por interacciones intersubjetivas entre las integrantes. Así, la expectativa es que este trabajo sirva de incentivo para otras experiencias de esa naturaleza, teniendo en vista contribuir con la formación de un investigador multiplicador e independiente, que sepa dialogar con el mundo de la vida.

Palabras clave: Grupo de Análisis Narrativo Discursivo. Formación de investigadores. Análisis narrativo discursivo grupal. Constitución de grupo.

\section{Introdução}

Neste artigo, são expostos os resultados de uma investigação de tese que emergiu no Grupo de Pesquisa Trajetórias de Formação (GTFORMA/ UFSM-RS), a partir de uma pesquisa que propunha a análise do corpus no contexto grupal. Nesta análise, as ideias foram amadurecendo e ganhando motivação para o estudo da constituição coletiva, uma vez que, nesse movimento, percebemos que as pesquisadoras ${ }^{1}$ encontravam-se em formação, numa constante aprendizagem que ia evoluindo, à medida que cada uma construía e aprimorava seu conhecimento na experiência prática coletiva.

Nesse contexto, concebemos o investigador como protagonista, pois deve saber lidar com o compromisso ético-político-social da atividade de pesquisa. Portanto, a nosso ver, a formação de pesquisadores demanda não só o desenvolvimento de habilidades intelectuais requeridas pela prática profissional (seja como produtores de novos conhecimentos, como orientadores ou avaliadores de produção científica), mas também, e talvez o mais importante para nós aqui, como um sujeito/pesquisador, capaz de se colocar no lugar do outro, de aprender com a crítica do outro, permitindo-se dar continuidade 
ao que já está posto, dispondo-se a tentar melhorar aquilo que pode ser melhorado.

Para essa tarefa de análise no coletivo, o GTFORMA que, por meio de um consenso entre as integrantes, resolveu denominar-se Grupo de Análise Narrativa Discursiva² (GAND), esteve engajado na apreciação das narrativas expressas nas entrevistas, realizadas com 60 professores de diferentes áreas de conhecimento. $O$ grupo decidiu denominar-se assim, porque era esse coletivo, com essas pessoas, que estava trabalhando, naquele momento, na pesquisa que iria se constituir. Portanto, o GTFORMA foi o lugar e o espaço no qual se constituiu o GAND.

Como opção teórica para fundamentar o marco epistemológico do trabalho, optamos pela Teoria da Ação Comunicativa (TAC), do filósofo alemão Jürgen Habermas (2012). Essa teoria nos possibilitou compreender que Habermas propõe uma emancipação humana por meio de um conceito de evolução e de integração social.

Dessa forma, escolhemos, como procedimento de interpretação da constituição do grupo, a abordagem hermenêutico-reconstrutiva. Lançamos um olhar-diagnóstico ao campo empírico, procurando desvelar padrões de racionalidade, expressos pelo conjunto em sua constituição. Podemos entender racionalidade como o homem percebe, interpreta, compreende e pronuncia o mundo da vida, nos mais diferentes momentos e aspectos. Para tanto, estabelecemos, como parâmetro de pesquisa, dois padrões de racionalidade: o paradigma da subjetividade moderna (do sujeito, da consciência) e o da razão comunicativa (HABERMAS, 2012 ), em que buscamos reconhecer as implicações do referido coletivo, como dispositivo de formação de pesquisadores e a sua contribuição para a construção de uma Análise Narrativa Discursiva Grupal (ANDG), ancorada numa racionalidade comunicativa.

paradigma da subjetividade é o da dominação. É o que opera sozinho, procurando afastar as pessoas e torná-las meio para um fim pré-determinado tecnicamente. Por isso, ele se sustenta na racionalidade técnica, visto que oculta, com o véu da neutralidade, os objetivos da dominação. A subjetividade está dependente da inserção de sujeitos num mundo compartilhado, onde existem saberes e normas que são acordados e em que fixam nossas ações.

Em contraposição ao paradigma da subjetividade, no paradigma da racionalidade comunicativa, temos outro modo de compreender e fazer 
acontecer a educação. Nesse, a educação é elaborada e conduzida de forma muito mais abrangente, natural, autêntica, compromissada com a emancipação e com a organização solidária das pessoas. A intersubjetividade tem a ver com a interação entre diferentes sujeitos, que constitui o sentido cultural da experiência humana. Podemos acrescentar ainda que ela foi incorporada pela TAC, de Habermas, e é entendida, nesse caso, como uma condição inerente à situação humana (no mundo da vida), e a linguagem é o médium indispensável de sua interação.

Entendemos que, neste espaço de equipe, em que o grupo se encontrou trabalhando, era possivel fazermos a conexão entre a compreensão e a validade, pois havia a possibilidade da correspondência dialógica, conforme Habermas preconiza.

\section{Procedimento investigativo}

A pesquisa caracteriza-se como qualitativa, uma vez que é pensada e gestada com base na participação dos sujeitos, ou seja, "[...] são qualitativas porque não existe relato ou descrição da realidade que não se refira a um sujeito" (DEVECHI; TREVISAN, 2010, p. 3).

Tendo, como pano de fundo, a TAC, de Habermas (2012), identificamos, interpretamos e compreendemos a dinâmica constitutiva do GAND para a elaboração de uma ANDG. Via abordagem hermenêutico-reconstrutiva, analisamos os discursos dos sujeitos da pesquisa, com base em dois modelos amplos de racionalidade: a filosofia da subjetividade ou da consciência e a filosofia da intersubjetividade, presentes nos aportes teóricos, de Habermas (2012).

Para a pesquisa, vinculada à Universidade Federal de Santa Maria, localizada no interior do Estado do Rio Grande do Sul, tivemos como contexto - GTFORMA. Os sujeitos foram representados por integrantes do novo grupo que se intitulou GAND. A participação da líder do GTFORMA, de estudantes e ex-estudantes de mestrado e doutorado, estudantes de iniciação científica e participantes externos, que se engajaram para realizar uma ANDG, foi fundamental. $\bigcirc$ GAND, do qual a autora deste trabalho também faz parte, iniciou com 19 integrantes e finalizou com 17 pessoas, todas do sexo feminino. 
O GAND teve 25 encontros no tołal. Porém, analisamos 15 reuniões, porque, nesses encontros, é que ocorreu a sua constituição. Assim, como coleta de informações, efetivaram-se os 15 encontros, que foram transcritos; entrevistas semiestruturadas com os subgrupos ${ }^{3}$ formados dentro do coletivo maior, cujo objetivo foi registrar e compreender como ocorreu essa organização, quais impressões tiveram do trabalho coletivo desenvolvido e o entendimento de cada uma sobre a pesquisa. Também utilizamos, como apoio, o diário de campo da pesquisadora, que serviu para complementar as informações. Visando a preservar a identidade das integrantes do GAND, elas são identificadas, no corpo deste trabalho, como IGAND I, IGAND2, IGAND3 e, assim, sucessivamente. As questões propostas às integrantes foram perguntas sem uma sequência pré-estabelecida e serviram como guia para a entrevistadora.

Após a transcrição das reuniões e das entrevistas, foram escolhidos recortes para análise, selecionados conforme os objetivos da proposta, com marcas de racionalidade, que revelam um determinado modelo de comportamento humano, entendido como uma manifestação inata da capacidade humana. Desse modo, as marcas de racionalidade, encontradas nos discursos das integrantes, possibilitaram a interpretação dos sentidos apresentados por elas, para desvendar a constituição do GAND a partir da compreensão das duas formas de racionalidade: a filosofia da subjetividade e a filosofia da intersubjetividade.

Com o intuito de melhor explicar a metodologia adotada, a seguir, apresentamos uma figura ilustrativa. 
Figura 1

\section{Esquema demonstrativo da metodologia adotada na pesquisa}

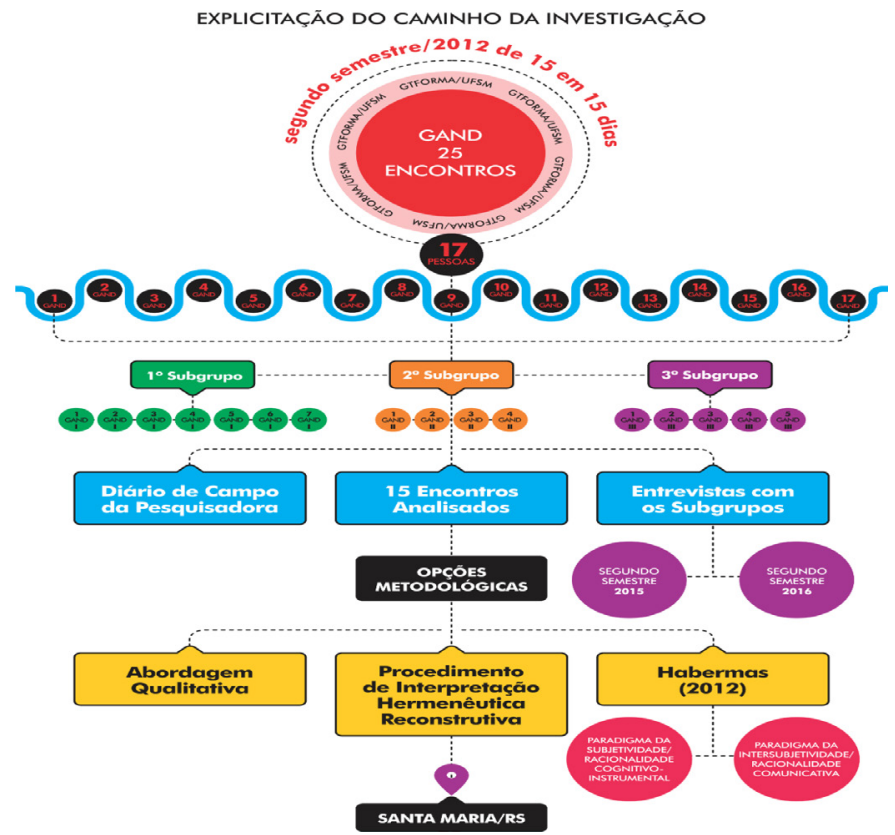

Fonte: Elaborada pela autora.

Diante disso, vale ressaltar que o processo constitutivo do GAND atravessou diferentes momentos, divididos em fases. A fase inicial, composta de cinco encontros, foi chamada de fase do conflito. É o momento em que o grupo se encontrou mais fragilizado, ansioso, disperso e preocupado, pois apresentou uma não compreensão do trabalho a ser realizado. Já a fase intermediária, identificada como fase da conceituação, composta por quatro encontros, foi a continuação de um pensamento conturbado, confuso, em que a ansiedade, causada pelo medo do desconhecido, permanecia. Contudo, ao mesmo tempo, houve uma transição, em que percebíamos um grupo mais aberto, maduro e voltado à concretização do trabalho. Ocorreu aqui, nesta etapa, a contextualização de experiências por meio de informações e fundamentação teórica, disciplina intelectual, que permitiu tornar mais esclarecedora a proposta e, consequentemente, proporcionou a síntese do processo. Mais conceitos surgiram de leituras e debates, permitindo a sensibilização de aspectos 
pessoais e interpessoais, que levaram à aprendizagem, baseadas na vivência de cada uma. E a fase final, nomeada de fase da constituição, formada por seis reuniões, foi o momento em que identificamos, entre as integrantes, um esforço para a resolução dos conflitos, demonstrando habilidade em comunicar ideias em situações individuais e de grupo. Nesta fase, em que houve a confirmação da análise, o grupo se consolidou e apresentou resultados em relação à constituição do GAND, como formação de pesquisadores.

Na descrição dessas 3 fases, apareceram várias características, discutidas como categorias. Dessa forma, essas categorias deram continuidade ao debate, pois as estreitamos em três dimensões para, enfim, compreendermos a dinâmica constitutiva do GAND. É preciso salientar que essas dimensões abarcaram cada uma das fases, as características e as categorias encontradas, conforme podemos visualizar na Figura 2 abaixo.

\section{Figura 2}

\section{Esquema demonstrativo das dimensões encontradas}

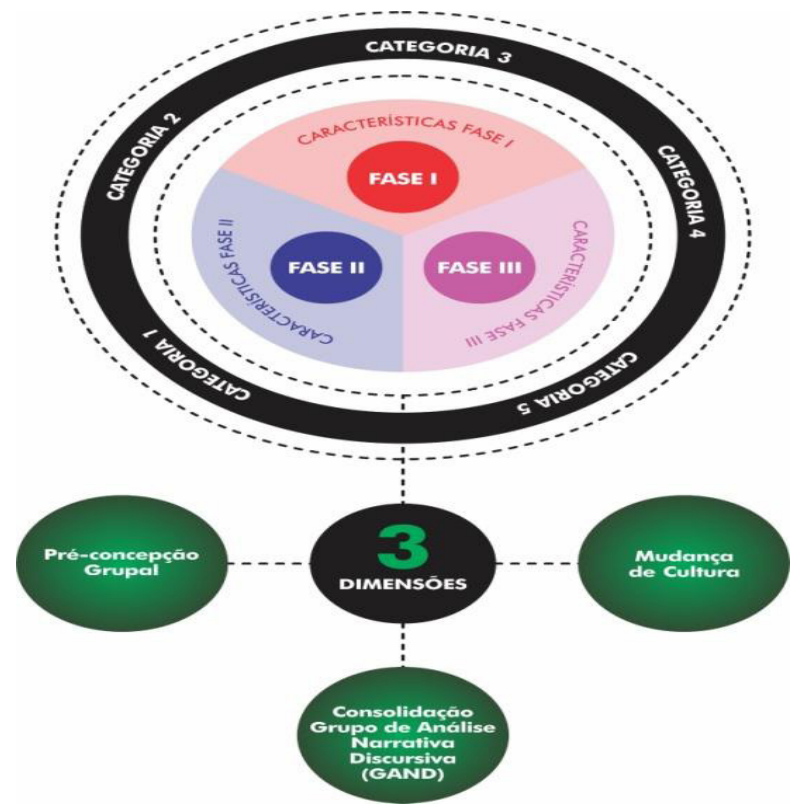

Fonte: Elaborada pela autora 


\section{Teoria da Ação Comunicativa (TAC)}

Ao compreendermos que constituir um grupo de pesquisadores é fazer "comunicação pedagógica", estamos sugerindo que essa área tem uma "racionalidade comunicativa". $\bigcirc$ que nos leva a essa conclusão é o fato de a comunicação despontar como elemento principal, em todos os momentos do processo de organização e desenvolvimento de um grupo. O participante precisa saber o que está sendo proposto no grupo; precisa estar em diálogo permanente com os seus pares para ficar por dentro da proposta. A racionalidade comunicativa vem dessa característica do contato, do diálogo e não de uma relação em que um sujeito emite a informação e o outro apenas recebe.

Refletindo sobre o que estamos discutindo: "constituição de um grupo de pesquisadores baseada numa racionalidade comunicativa", deparamo-nos com o pensamento de Habermas, especificamente com sua "Teoria do Agir Comunicativo" (2012). Esse autor, embora não tenha se dedicado a pensar o universo da educação ${ }^{4}$, estruturou reflexões que possibilitam entender melhor qualquer situação vivencial, baseada em relações comunicativas.

A virada linguística, conforme Habermas, é a transição do paradigma subjetivo para o intersubjetivo. Segundo o autor, "[...] a guinada linguística havida na filosofia preparou os meios conceituais através dos quais é possível analisar a razão incorporada no agir comunicativo" (HABERMAS, 1990, p. 53). Com base nessa transição, a linguagem passa a ter importância no contexto atual da filosofia, pois a "virada linguística" propiciou o reconhecimento da razão, que opera na prática comunicativa cotidiana. Essa é o meio pelo qual se forma e se reproduz tudo o que diz respeito à cultura, à vida social e à formação da personalidade dos indivíduos. Nesse processo, entendemos a linguagem como a maneira mais natural e verdadeira para todos os entendimentos mútuos. $\bigcirc$ conceito de entendimento remete a um "[...] comum acordo almejado pelos participantes e racionalmente motivado, que se mede segundo pretensões de validade criticáveis" (HABERMAS, 2012a, p. 147). Assim, a linguagem propicia os entendimentos, o consenso, os acordos que um grupo de sujeitos que dialogam entre si requer.

A mudança da subjetividade - princípio fundamental da filosofia da consciência - para a intersubjetividade permite estabelecer a diferença entre uma relação dialógica (sujeito-sujeito), e uma relação instrumental (sujeito-objeto), ampliando o caráter interativo da educação. Corroborando com as 
palavras de Hermann (2004), podemos dizer que o conceito de ação comunicativa ajuda a esclarecer o problema das relações entre subjetividade e intersubjetividade na ação pedagógica, diante do fracasso das tentativas de entender a educação, como essencialmente interativa e não mais embasada na relação meio-fim. Segundo Habermas (2012a), ações orientadas a um fim são aquelas destinadas a solucionar problemas. Portanto, é fundamental buscarmos uma relação intersubjetiva no processo educativo, de modo que não priorizemos a relação meio-fim. Habermas indica que a intersubjetividade é possível, pois a entende como "linguagem" e "mundo da vida", como práxis comunicativa. Para o autor, o Mundo da Vida é, a princípio, um mundo intersubjetivo, ou seja, a estrutura básica da realidade comum a todos. "O mundo da vida constitui, pois, de certa forma, o lugar transcendental em que os falantes e ouvintes se encontram" (HABERMAS, 2012b, p. 231). Ou seja, é toda a realidade contextual. Assim, entendemos que a ação é essencial para a interação e somente acontece, porque nos encontramos com outros num mundo compartilhado.

Habermas, ao distinguir os tipos de ação social em agir estratégico e agir comunicativo, não está desconsiderando nenhum nem outro. Pelo contrário, ressalta que um agir complementa, está ligado ao outro. $\bigcirc$ que o autor traz é a discussão desses tipos de agir. Ou seja, ao priorizar a dimensão intersubjetiva do conhecimento, explica que se valoriza não mais o produto a ser alcançado, mas a proporção dos procedimentos. De acordo com Habermas (2012a), os conhecimentos são efeitos de um processo de entendimento entre indivíduos sobre algo, visto que entende que a razão comunicativa ainda sobrevive nas ações do dia a dia.

\section{A hermenêutica}

Em relação à hermenêutica, Habermas (2012b) afirma que é preciso primar por uma compreensão autorreflexiva e crítica, baseada no distanciamento metodológico do objeto da compreensão. Isso quer dizer que devemos reconhecer o poder da reflexão para criticar nossos preconceitos herdados. Contudo, o autor declara que isso não significa que toda metodologia seja suspeita. $\bigcirc$ que ocorre é que, ao adotar a compreensão autorreflexiva, o intérprete permite a aplicação do método num sentido diferente daquele do método 
A formação de pesquisadores no espaço grupal

das ciências naturais. Dessa forma, concordamos com Habermas, isto é, é fulcral perceber o poder da reflexão que se desenvolve na compreensão, pois ela sacode as doutrinas da prática da vida. A reflexão desenvolve um poder retroativo que pode nos fazer entender por que ele foi aceito. Como "hermenêutica profunda", a hermenêutica crítica procura as causas da compreensão e da comunicação distorcidas, que atuam a coberto de uma interação aparentemente normal (HABERMAS, $2012 \mathrm{~b}$ ).

Assim, o que propomos neste estudo foi a compreensão hermenêutica como um processo de formação que se realiza por meio da linguagem. A relação formativa autêntica, para Habermas, é a que não apresenta um ponto estável, mas o movimento dialético de um aprender intersubjetivo constante. Para o autor, a linguagem também é formada dentro do processo histórico por modos de produção e relações de poder social. Essas relações de trabalho e poder na sociedade podem ser examinadas por meio da reflexão, para que seja realizada uma crítica das estruturas herdadas. Somos influenciados, desde sempre, pelas tradições, porque as mesmas fazem parte do mundo da vida.

Para atender às exigências atuais de um processo mais coletivo, torna-se relevante a inserção de processos dialógicos no contexto educativo, que resulta em compreensões críticas e ações comunicativas. Para tanto, apostamos na ideia de recuperar o entendimento por meio de ações comunicativas, pois promovemos uma discussão sobre como os pesquisadores estão se formando, procurando soluções e tratamento para os problemas existentes, ao nos lançarmos numa proposta inovadora. Entendemos que era possível estabelecermos acordos num espaço coletivo, sem restringir e desconsiderar o que é diferente. Para a abordagem hermenêutico-reconstrutiva, o sujeito é comunicativo e visa ao consenso. Nessa visão, o sujeito tem mais força que o objeto no processo de significação, contudo não descarta a existência do objeto. Há um descentramento do sujeito em que o outro passa a ser a categoria central das pesquisas (DEVECHI; TREVISAN, 2010). Desse modo, ao inserirmos o outro no processo, como elemento principal, estaremos também exercendo a alteridade, ou seja, dando o primeiro passo para reconhecermos que é, na diversidade, que aprendemos, que é com o diferente que crescemos, permitindo-nos compartilhar saberes, a fim de desenvolvermos uma aprendizagem evolutiva. Portanto, essa abordagem se caracteriza pelo "[...] descentramento do sujeito justificado diante do outro, o qual tem a tarefa de aceitar ou não as pretensões de validade do discurso" (DEVECHI; TREVISAN, 2010, p. 7). Diante 
disso, o pesquisador orienta o seu agir, segundo o "[...] pressuposto de análise das crenças pela aceitação pública, sendo o seu télos o acordo racionalmente motivado" (DEVECHI; TREVISAN, 2010, p. 7).

A hermenêutica se realiza pela linguagem, pois essa indica a ligação que temos com o passado, com a tradição, resultando em apropriação e interpretação. Assim, a pesquisa parte do reconhecimento de que a nossa compreensão depende da linguagem. Essa se realiza num espaço coletivo, em que pessoas, com formações diferentes, divergem, muitas vezes, na forma de pensar, mas que, por meio do diálogo, superam seus próprios horizontes interpretativos, em busca de um entendimento sobre o objetivo comum. Sendo assim, o mais importante, nessa pesquisa, foi o diálogo realizado entre os sujeitos no espaço coletivo, sempre com a possibilidade de se retornar ao que já havia sido discutido e realizado anteriormente, em relação aos diferentes autores e teorias.

\section{Leitura e interpretação das racionalidades do GAND Pré-concepção grupal}

A partir do diálogo com as participantes do GAND e das transcrições das reuniões, observamos que as mesmas, quando falavam, concretizavam, em seus discursos, uma trajetória marcada por grandes momentos de tensão, em relação ao trabalho desenvolvido. Esta dimensão nos remete à análise do momento conturbado pelo qual o GAND passou, pois, na fase do conflito, observamos as integrantes fragilizadas, ansiosas, dispersas e preocupadas. Apresentavam uma não compreensão do trabalho a ser desenvolvido, conforme verificamos nas expressões "eu não entendi ainda o que é para fazer!" (IGAND4, Grande grupo, 20 12), "não sei se eu entendi bem, existe um grupo de pesquisadores e a proposta é que em alguns momentos possa ser utilizada uma técnica. É isso?" (IGAND13, 2012, Grande grupo). Contudo, mesmo não havendo uma compreensão acerca da proposta, era visivel a necessidade de tomada de decisões, conforme o discurso "gurias eu tô apavorada... Nós vamos ter que chegar a uma decisão em grupo (IGANDI, 2012, Grande grupo). Segundo Habermas (2012a, p. 156), "sob a pressão de tomar decisões em uma dada situação de ação, o leigo participa de interações com a intenção de coordenar as ações dos envolvidos por meio de um processo de 
entendimento mútuo". $\bigcirc$ processo interpretativo cooperativo serve para pôr à prova a validade de componentes problemáticos do saber, mesmo o sujeito participando de interações. Ou seja, "[...] o fim não está na coordenação de ações, mas na crítica e expansão do saber" (HABERMAS, 201 2a, p. 157).

Para as integrantes do GAND, a experiência de análise coletiva Ihes oportunizou o desenvolvimento de uma nova maneira de organização do tempo e dos mecanismos de estudo aos quais não estavam acostumadas. Apontam, como maior dificuldade encontrada, a conciliação de horários e aceitação do pensamento e produção do outro. Para elas, num trabalho em grupo, o que determina o ritmo das tarefas está intimamente ligado ao ritmo da disciplina que o grupo deve impor para a realização dos trabalhos previstos. As narrativas das integrantes que seguem confirmam essa ideia:

Acho que conciliar os horários. Às vezes fazíamos os encontros via Skype (IGAND 15, 2016).

Conseguir que todo mundo realmente viesse nos horários tem que ter disciplina, sistematização para atender a proposta de fazer a análise no coletivo (IGAND 13, 2015).

Foi essa racionalidade que nos permitiu supor que esses sujeitos estão inscritos em uma formação discursiva que, consequentemente, remete-nos ao agir estratégico, orientado pela lógica instrumental e voltado ao sucesso e aos fins de controle e dominação.

Chegar aqui e trabalhar junto, para mim, foi muito difícil, porque tem que se sentar e ouvir, e não resolver na hora. É um exercício (IGAND4, 2015).

Tínhamos modos de pensar diferentes sobre o mesmo objeto, sobre a mesma situação...e chegar a um acordo foi muito complicado. Tínhamos que refletir muito... (IGAND13, 2015).

Observamos que, para alguns integrantes, o pensamento grupal foi muito exigido. $\bigcirc$ trabalho coletivo demandou que fossem responsáveis pela construção do conhecimento por meio da reflexão. Assim, não podemos deixar de pensar nessa questão da formação por meio do pensamento reflexivo, pois ele pode estar vinculado à filosofia da consciência. $\bigcirc$ projeto da modernidade filosófica e pedagógica se fundamenta no poder absoluto e no exercício pleno da razão, que se manifesta em forma de reflexão. Portanto, é o exercício de 
uma competência cognitiva e não, necessariamente, uma competência interativa, discursiva e comunicativa. É isso que caracteriza um e outro paradigma.

Dando continuidade a esse pensamento, na fala da integrante abaixo verificamos uma regularidade na utilização da expressão "É que eu acho que essa análise do grupo de vocês..." (IGAND12, 2012, Grande grupo). Foi essa racionalidade que nos propiciou ver que, para uma e outra das integrantes, o grupo ainda não lhes pertencia. Não havia um sentimento de pertença. Acreditamos haver, nesse recorte, um apontamento para a ressignificação da relação entre o indivíduo, o grupo e o processo de construção do conhecimento. A racionalidade que perpassa o discurso desta integrante é remetida a uma discursividade própria do agir instrumental, pois entendemos que há um deslocamento no processo de se sentir membro de um grupo, participante da categoria do agir comunicativo para do agir instrumental. De acordo com o discurso dessa integrante, a interação deixa de ser entendida como um processo e é significada principalmente por "apenas estar em algum lugar". Verificamos uma forte tendência a uma racionalidade instrumental no contexto das relações entre as pessoas.

Nesse sentido, ainda no que se refere à interação no GAND, muitas das propostas em grupo se apresentam como "interativas" e justificam sua própria qualidade no fato de produzirem condições amplas de contato entre os integrantes. A ideia de interação, contudo, na maioria das vezes, não chega ao nível de importância que a ela estamos atribuindo aqui. Segundo Habermas (2012), ações comunicativas sempre exigem uma interpretação que seja racional desde o início. O nível de interação foi fundamental para que o grupo pudesse evoluir, mesmo apresentando momentos de atrito e algumas atitudes de hostilidade. Vejamos:

Em vários momentos se percebeu uma 'falta de coesão de ideias dos subgrupos' laté compreensível pelas diferentes formações que temos) onde transparecia que o colega com maior empoderamento e poder de persuasão conseguia defender melhor sua ideia no subgrupo e esta ideia era apresentada então como a do subgrupo ao grande grupo (IGAND3, 2016 , Entrevista no subgrupo).

Podemos observar, nesse recorte, que a integrante, ao mesmo tempo em que se mostra "satisfeita" com o relacionamento que mantinham dentro do grupo, também remete, em seu discurso, a algo inscrito em outra 
A formação de pesquisadores no espaço grupal

formação discursiva: a da rivalidade, da disputa de poder entre os subgrupos. Claramente percebíamos a necessidade de alguns subgrupos se sobressaírem. Havia uma concorrência velada que talvez tenha nascido pela condição de se considerarem aquém dentro do grupo, da dúvida de poder não estar correspondendo aos anseios da líder, visto que alguns subgrupos se apresentavam mais organizados e produtivos, efetuando várias publicações de artigos das análises que vinham fazendo. A partir daí, foi possível observar que algumas integrantes se desviavam do comportamento desejado, utilizavam-se de estratégias para "forçar" divergências, pois havia uma tendência em não aceitar, propositalmente, a ideia, as análises/pensamento das colegas, gerando desentendimento, desacordo e um conflito interno. Uma e outra participante não resolvia suas dúvidas interagindo com o grupo. Pelo contrário. É como se elas não aceitassem a evolução coletiva do grupo e buscassem uma atenção individual, seja das demais participantes ou da líder. No nosso entendimento, esta foi outra forma encontrada por constituintes para tentarem mostrar seu "poder". Elas burlam a ideia de trabalho coletivo e passam a se comunicar por outros meios. Além disso, havia as que optavam pelo silêncio. Somente participavam com a escuta, sem se manifestar. Fica então a dúvida se, nessas 14 posturas, existe a preservação da neutralidade ou a tentativa de se eximir dos conflitos. Com isso, reiteramos que a existência de estar em grupo não significa que os envolvidos no processo de análise vão ser capazes de "dialogar".

Como pudemos ver, muitos dos discursos da primeira fase do GAND (fase do conflito) ainda apresentam elos com os ideais propostos pela filosofia da consciência, ou seja, a formação de um sujeito centrado apenas na sua visão de conhecimento e no seu "eu". Contudo, observamos também, nas comunicações cotidianas do grupo, momentos explorativos voltados ao conhecimento, em que não desvincularam o momento criativo e construtivo, orientado a que se alcançasse um consenso, conforme Habermas preconiza. Conforme o autor, o intérprete não pode alcançar a pré-compreensão do contexto, se não participa do processo de formação e avanço desse contexto.

\section{Mudança de cultura}

Nesta pesquisa, para a compreensão das interações, um conceito significativo da teoria habermasiana é o de "coordenação de ações" (HABERMAS, 
20121, tendo em vista o entendimento de que o diálogo é possível em um espaço grupal. Quanto a isso, o autor define um agir coordenado como:

A necessidade de agir coordenado gera na sociedade uma determinada demanda de comunicação; e essa demanda precisa ser atendida quando, para cumprir o propósito de satisfazer essa carência, é obrigatoriamente possível uma coordenação efetiva de ações (HABERMAS, 201 2a, p. 477).

Em outras palavras, para o autor, a coordenação de ações de um grupo de falantes acontece por meio de ações individuais, construídas coletivamente, objetivando o entendimento dos participantes sobre suas pretensões de verdade. Assim, para Habermas (2012a), a racionalidade comunicativa acontece como uma maneira de interagir com o mundo, por meio da interação intersubjetiva entre os envolvidos, ao fazerem uso da linguagem.

Nesse sentido, enfatizamos a questão da qualidade no processo de análise coletiva que, para nós, quando pensamos em "qualidade", é, antes de tudo, a qualidade do processo comunicacional. Em outras palavras, quando analisamos a qualidade num grupo de pesquisa, estamos tratando das condições que os sujeitos produzem para vencer o primeiro problema que é de "comunicação".

Fica claro que se trata de um grupo de pesquisadores com um comportamento diferenciado, ou seja, um grupo agitado que apresenta facilidade para se dispersar e perder constantemente o foco do trabalho. Além disso, nesta fase, o GAND atingiu o ponto máximo das incertezas. $\bigcirc$ movimento que se estabeleceu dentro do grupo era de oscilação entre a tensão e a necessidade de sistematizar o trabalho. Na atuação impositiva de parte das integrantes, ao distribuirmos as tarefas, percebemos os reflexos da racionalidade instrumental. Vejamos:

Por sorteio o risco de errar é menor! (IGAND9, 2013, Grande grupo).

Mas tem que ser uma coisa uniforme... (IGAND5, 2013, Grande Grupo).

Eu acho melhor por sorteio também! (IGAND8, 2013, Grande Grupo). 
A formação de pesquisadores no espaço grupal

Então vamos pegar os 60 sujeitos e dividir para cada pessoa do grupo um número x. Pronto!! Termina essa função... (IGAND5, 2013, Grande Grupo).

Contudo, podemos notar que há progressão na discussão do assunto pelos integrantes do GAND, ao apostarem na pertinência da proposição de um ambiente de possibilidades de debate e compartilhamento de ideias, como forma de fazer emergir, coletivamente, elementos necessários à construção de um aporte metodológico que sirva de fundamentação para uma análise coletiva. Também podemos considerar um ponto importante dentro da TAC (2012) a necessidade de os debatedores esgotarem seus argumentos em defesa de uma proposição, na busca do entendimento e consenso no grupo. Isso se torna claro, dentro do GAND, a partir do momento em que as integrantes tentam buscar princípios comunicativos num processo de interação. Vejamos:

Análise narrativa grupal poderia ser? (IGAND 14, 2013).

Pode ser, vamos repetir para o gravador...Grupo de Análise Narrativa Grupal. Grupo de Análise Narrativa acho que fecha mais, né? (IGAND1, 2013).

É que análise narrativa é nós, grupo, nos constituindo (IGAND4, 2013).

Isso... é nós nos constituindo e essa é a metodologia do nosso projeto. O nome da metodologia pode ser Análise Narrativa Grupal. (IGAND1, 2013).

Bom, pelo menos chegamos num consenso (IGAND2, 2013).

Podemos ver, nos trechos de interação acima, um conjunto de elementos de fala que contemplam uma discussão, mesmo que de pequena extensão. As integrantes, ao contemplarem uma temática específica, que era o nome do grupo e o nome da metodologia, discutem em favor do melhor argumento. Segundo Habermas (2012a, p. 67), "[...] o desenvolvimento de um argumento não é de modo algum a unificação amigável em vista de opiniões quaisquer". Ou seja, posições divergentes devem servir para a construção do conhecimento e não para a disputa. Transições do pensamento cumprem-se em nós, sem importar se elas nos agradam ou não.

Ações comunicativas sempre requerem uma interpretação que seja racional desde o início. Portanto, mesmo que o GAND não tivesse a compreensão exata da sua dinâmica de trabalho, foi, a partir das interações e da 
coordenação de ações individuais, tendo por base um comum acordo, que o grupo alcançou o entendimento da proposta. As expressões para o estabelecimento de relações interpessoais, entre falante e ouvinte, deram espaço para o amadurecimento das ideias, gerando a síntese do processo.

\section{Consolidação do GAND como formação de pesquisadores}

Entendemos que os encontros do GAND para análise coletiva, com o passar do tempo, foram gradativamente mudando a maneira habitual de participação das integrantes no processo de reflexão e ação, especificamente sobre concepção de pesquisa e sobre a metodologia da pesquisa. Aos poucos, fomos nos deparando com um cenário mais caracterizado pela revisão permanente do estado das coisas e, consequentemente, um retorno constante às conclusões das análises nos subgrupos. Esse trabalho proporcionou a discussão dos passos dados, e as integrantes puderam manifestar muitas requisições de inteligibilidade sobre o exercício de criação da metodologia, bem como os avanços, os entraves e as conquistas manifestadas pelos pesquisadores em relação ao trabalho desenvolvido.

Essas discussões em grupo estão ligadas, fundamentalmente, aos aspectos da ação comunicativa e foram mostradas em quase todas as integrantes, em grande parte, ao longo dos quinze encontros, mais especificamente no final. Sendo assim, evidenciamos também o trabalho de liderança que, mediante uma comunicação aberta, foi fomentada pelo incentivo à busca pelo entendimento entre as integrantes.

contexto do GAND permite apresentar a premissa teórica de que o incentivo frequente da líder à análise coletiva de narrativas e a constituição de um ambiente que preze pela ação comunicativa podem ser tomados como um processo formativo de pesquisadores. Dessa forma, a interação entre as integrantes do GAND, possibilitada pela análise coletiva, permitiu interações intersubjetivas como as preconizadas por Habermas (2012). Essa é uma característica essencial no processo comunicativo pelo caminho da TAC, no que tange à questão da qualidade comunicacional nos grupos de pesquisa. Nesses, a pesquisa é colocada como um meio adequado de aquisição e de construção do conhecimento. Contudo, é preciso que se conheça que tipo 
A formação de pesquisadores no espaço grupal

de pesquisa está sendo privilegiado, ou seja, em quais princípios de conhecimento eles se apoiam.

Assim, a essência de muitos dos discursos das integrantes contempla categorias já superadoras da filosofia do sujeito, como, por exemplo, a aplicação da atividade atravessada por uma intencionalidade, por uma reflexão constante da situação vivenciada e por um plano de ação mediado pela teoria; o aprendizado da convivência; o afeto transformador e a escuta em processos de cooperação, que privilegiam a inteligibilidade. Tudo isso favoreceu a comunicação e a conquista de entendimentos. Ratificando os escritos de Habermas, o contato entre a líder e as integrantes gerou um processo de "coordenação das ações" em que a intersubjetividade foi estimulada entre as integrantes durante todo o tempo; por isso, percebemos que a proposta de análise coletiva prevê a interação entre os envolvidos.

Observamos, no GAND, o desenvolvimento de um espaço que, com o passar do tempo, mesmo ainda tendo presente a ansiedade, as dúvidas, o egocentrismo, houve aceitação, tolerância e escuta em relação ao ponto de vista das integrantes, possibilitando o debate aberto e igualitário sobre a pesquisa. Havia uma discussão sobre as preocupações por meio das experiências

18 nos subgrupos, colocando-se em dúvida e se questionando sobre a validade da forma como as análises estavam sendo conduzidas.

Vocês conseguem identificar todos esses detalhes da fala na entrevista, do que os sujeitos estão transmitindo? (IGAND3, 2013).

Não tem como pra mim... Porque algumas narrativas que tu recortas, se tu não explica, eu não entendo (IGAND4, 2013).

Mas eu acho que não é porque eu fiz, acho que é porque eu sou da área. (IGAND8, 2013).

Sim, a gente reparou que quando o sujeito é da nossa área conseguimos discutir coisas que nos outros não (IGAND3, 2013).

$\bigcirc$ que tu diz é verdade, não tem como não passar pela compreensão da gente, mas também tem que procurar se manter mais neutro e recortar mais a mensagem da pessoa (IGAND2, 2013).

Nesses discursos, a imersão e o envolvimento das integrantes em uma coordenação de ações para a análise coletiva se deu ao longo dos encontros. Isso aconteceu pelo fato de elas irem se envolvendo na pesquisa, nas apresentações das avaliações e no debate de pretensões de validade e, aos poucos, construindo entendimentos sobre a elaboração das ideias e as ações 
que faziam parte do estudo em equipe. Dessa forma, foram sintetizando o processo analítico e fortalecendo suas concepções no mundo da vida (HABERMAS, $2012 a$ ), ao mesmo tempo em que propunham situações de aproximação entre as ideias trazidas para o grande grupo e constituíam o que chamamos de um GAND. Segundo Habermas (2012a, p. 159), "[...] esse mundo da vida intersubjetivamente partilhado conforma o pano de fundo do agir comunicativo".

Assim, caracterizamos o trabalho de investigação em equipe como um processo no qual os saberes trazidos pelas integrantes, incluindo preocupações, dúvidas, angústias, são 'tematizadas' em um ambiente de busca constante por um entendimento dos conteúdos pragmáticos e proposicionais dos atos de fala (HABERMAS, 2012a) das integrantes, que somente pode acontecer na ação comunicativa. Esse dado, também, coopera na concepção de pesquisa e na constituição do GAND, juntamente com o envolvimento das integrantes como "coordenadores de ação". Em uma perspectiva habermasiana, o conceito de "coordenação de ações" é um elemento base nas análises de processos de interação.

\section{A constituição do Grupo de Análise Narrativa Discursiva (GAND)}

Ao final das análises, o GAND estava mais aberto e conquistava resultados excelentes. Houve um compromisso assumido por todas. Também existiu um alinhamento quando se tratava de apresentar os resultados. Mesmo tendo opiniões divergentes no grupo, os acordos resultavam do esforço de cada uma para se alcançar um posicionamento conjunto em relação à pesquisa. Tratava-se de uma solução mista, em que cediam e ganhavam, tornando possível a convivência e o crescimento do grupo. Isso amenizava conflitos não produtivos em relação à tomada de decisões, iá que a rigidez das posturas e a imposição de ideias de algumas, muitas vezes, reduziam o comprometimento com o trabalho. Essa avaliação permitiu a promoção da eficácia da comunicação intra e intergrupal que o grupo deveria ter. Assim, a dinâmica constitutiva do grupo passou por três momentos, a saber:

$\left.1^{\circ}\right) \bigcirc$ GAND foi se constituindo nos momentos de dúvidas e certezas. Esses momentos, que fizeram parte, principalmente, da pré-concepção grupal, tornou-o um grupo coeso. A coesão é o fator mais importante para nós, pois é o grau em que um grupo consegue manter-se unido, e não só no decorrer de 
cada tarefa, mas, sim, ao longo da vida acadêmica/profissional. Um grupo coeso, e também eficaz, é aquele que consegue enfrentar os desafios atribuídos e, mesmo após seu término, mantém-se unido em favor de outras pesquisas. E o GAND conseguiu manter-se unido, coeso pelas seguintes posturas: a) diferentes motivos pessoais/formativos compartilhados; b) definição de organização do trabalho (como íamos realizar as análises) de modo compartilhado; c) interação frequente (reuniões/grupos no WhatsApp/encontros informais); d) recompensas à cooperação (doutorado, mestrado, aprendizagem, currículo lattes, produções, etc.); e) avaliação e reconhecimento da eficácia do grupo (reconhecimento da líder, conclusão do relatório); f) respeito, fidelidade e gratidão pela líder do grupo.

$2^{\circ}$ ) De conceitos novos que iam surgindo a partir do lançamento de várias ideias, de divagações e, ao mesmo tempo, a partir do conhecimento específico que cada uma trazia, quando estava discutindo. Conhecimentos individuais, mas que eram partilhados no coletivo. Não era um grupo fechado. Era um grupo de ideias abertas, motivado.

$\left.3^{\circ}\right)$ Um grupo que ia se constituindo a partir do seu desmonte e se reconstruía por meio do constante incentivo da líder que, mesmo receosa 20 e preocupada com o andamento da pesquisa, conseguia instigar, motivar e mostrar que o aprendizado acontece durante o processo. Portanto, dependia de cada uma ali exercer a disciplina que uma pesquisa requer para produzir o conhecimento.

Nossos estudos mostraram que as abordagens de aprendizagem, orientações de liderança, dificuldades e pontos de vista diferentes formam uma rede conectada. Portanto, a dinâmica constitutiva do GAND decorreu do esforço de construção de uma ANDG, gerando formação de pesquisadores, atravessada por interações intersubjetivas que possibilitaram, às integrantes, refletir sobre suas próprias práticas como pesquisadoras, gerando mudanças na forma de conceber e fazer pesquisa.

Assim, esses três momentos pelos quais o grupo passou permitiram duas movimentações importantes que constituíram o GAND: a) a reconstrução do equilíbrio entre os mundos objetivo, subjetivo e social; e b) a coordenação efetiva de ações individuais (imersão, exploração, elaboração e reelaboração) para o desenvolvimento da tarefa de análise coletiva proposta pelo grupo. 
Em relação à primeira movimentação, é necessário comentar que essa caracteriza o esforço individual e coletivo das integrantes para harmonizar e integrar as três dimensões: objetiva (ciência-tecnologia); subjetiva (cultura-indivíduo); e social (sociedade-coletivo). Houve uma superação em equipe que permitiu uma transcendência significativa da racionalidade instrumental para a comunicativa. Quando o GAND deixou de dar ênfase à dimensão objetiva, estabeleceu um equilíbrio entre as dimensões da objetividade, subjetividade e coletividade.

Neste processo de reconstruir a comunicação, o GAND viabilizou a evolução para uma fase mais avançada de racionalidade social. Atribuímos isso ao visível empenho e esforço demonstrado por parte de cada integrante para a busca de entendimentos. Isso as levou à imersão, exploração, elaboração e reelaboração do processo de análise que constituiu o GAND. Esse processo de imersão, exploração, elaboração e reelaboração é o que compreendemos como coordenação de ações, nossa segunda movimentação.

Consideramos essas duas movimentações como aglutinadoras e impulsionadoras do processo de constituição do GAND, pois, por meio das ações das integrantes e do visível progresso das discussões, o GAND alcançou o nível de entendimento necessário à consolidação da proposta. Esse processo de entendimento é identificável nas fases de constituição do GAND, em que a proposta de construção coletiva de análise foi atendida. A análise no espaço grupal, pautada no agir comunicativo, favoreceu o diálogo e a tomada de decisões, gerando ações que proporcionaram mudanças pessoais, profissionais e intelectuais nas integrantes. Esses resultados podem ser entendidos mais claramente na Figura 3 abaixo. 
Figura 3

\section{Esquema demonstrativo da dinâmica de constituição do GAND}

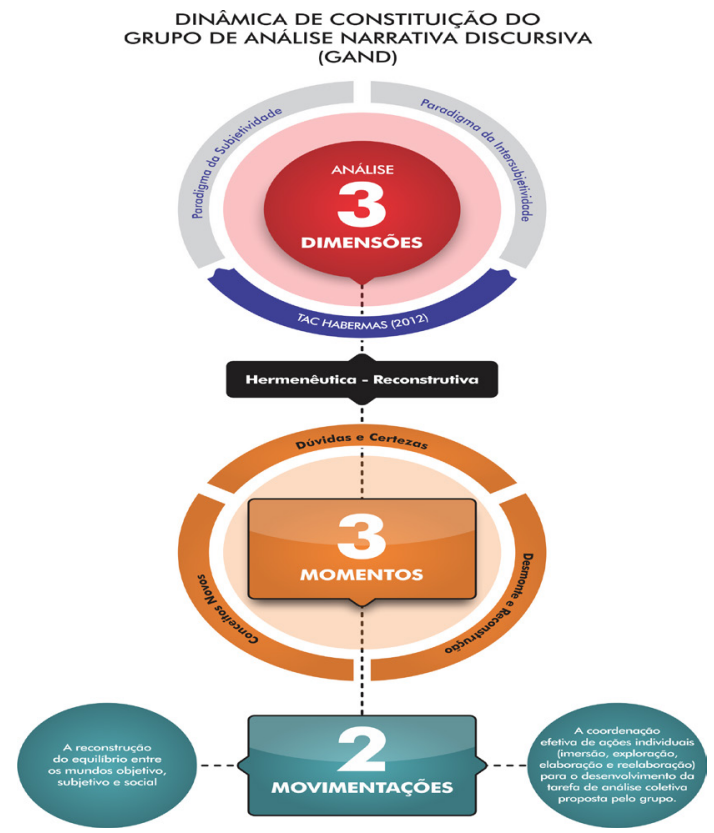

Fonte: Elaborada pela autora.

\section{Considerações Finais}

Neste trabalho, não tivemos a pretensão de dizer se o que se fez ou se faz atualmente nos grupos de pesquisa tem ou não qualidade. Coube-nos, como pesquisadoras, investigar a área e produzir algo sobre ela. No nosso caso, identificar, interpretar e compreender a dinâmica constitutiva do Grupo de Análise Narrativa Discursiva (GAND) para a elaboração de uma Análise Narrativa Discursiva Grupal (ANDG). Para tanto, procuramos aproveitar algum aspecto do pensamento de Habermas (2012) para enriquecer a área educacional, em especial na formação de pesquisadores. Portanto, este trabalho se constitui a partir da reflexão sobre a necessidade de apontarmos caminhos mais promissores para a formação do pesquisador. 
A principal contribuição desta pesquisa está na constituição do GAND, compreendido a partir dos discursos analisados sob a perspectiva do referencial habermasiano. Além disso, contribui com a Linha de Pesquisa (Formação, Saberes e Desenvolvimento Profissional), uma vez que, com este trabalho, o de analisar coletivamente as narrativas de professores, formaram-se pesquisadores, que é o objetivo principal dos grupos de pesquisa. Dessa forma, sugerimos um repensar nessa formação, de modo que sejam valorizados e implementados espaços que busquem desenvolver uma ação mais comunicativa entre os diferentes sujeitos que participam desses contextos. Para isso, é necessário também desenvolver teorias críticas e uma reconstrução conceitual que possam fundamentar uma racionalidade mais comunicativa, já que é concebida como uma capacidade intersubjetiva de tolerância, de compreensão, de argumentação e de comunicação.

Com base nisso, promovendo um ambiente de ação comunicativa, temos a chance de descentralizar a perspectiva de um pesquisador solitário, que chega a compreensões e conclusões apenas sob o seu ponto de vista e pelo seu próprio viés teórico. Ainda, temos a pretensão de que esta pesquisa se torne uma "pesquisa comunicativa", ou seja, capaz de fazer despertar a competência comunicativa dos pesquisadores, de modo que se permitam discutir e reavaliar o campo da pesquisa em educação, em benefício de todos. Por comungarmos da ideia de que a singularidade do sujeito se constrói no coletivo, alimentamos ainda a expectativa de que este trabalho de análise grupal sirva de estímulo a experiências formativas, tendo em vista contribuir com a formação de um pesquisador multiplicador e independente, que saiba dialogar com o mundo da vida.

\section{Notas}

1 Dentre os 17 membros do grupo, todos são do sexo feminino. Dessa maneira, no decorrer do texto, faremos sempre referência ao sexo feminino.

2 No texto, para evitar a repetida utilização da denominação do grupo em tela, quando houver recorrência a ele, muitas vezes, passamos a indicar, respectivamente, a sigla GAND - Grupo de Análise Narrativa Discursiva.

3 Dentro do grande grupo foram formados subgrupos com o intuito de agilizar o trabalho de análise.

4 Nas palavras de Bouflever (2001, p. 25): "[...] a pertinência dos conceitos habermasianos para a educação [...] não significa a possibilidade de sua aplicação simples e direta para situações pedagógicas". 


\section{Referências}

BOUFLEUER, José Pedro. Pedagogia da ação comunicativa: uma leitura de Habermas. 3. ed. ljuí: Editora Unijuí, 2001.

DEVECHI, Catia Piccolo Viero; TREVISAN, Amarildo Luiz. Sobre a proximidade do senso comum das pesquisas qualitativas em educação: positividade ou simples decadência?

Revista Brasileira de Educação, Rio de Janeiro, v. 15, n. 43, p. 148-201, 2010. Disponível em: http://www.scielo.br/pdf/rbedu/v15n43/a10v15n43.pdf. Acesso em: jul. 2016.

IGAND4. Entrevista no subgrupo. Santa Maria (Rio Grande do Sul), 14 ago. 2015.

IGAND 1 3. Entrevista no subgrupo. Santa Maria (Rio Grande do Sul), 14 ago. 2015.

IGAND3. Entrevista no subgrupo. Santa Maria (Rio Grande do Sul), 8 jan. 2016.

IGAND 15. Entrevista no subgrupo. Santa Maria (Rio Grande do Sul), 8 jan. 2016.

IGAND 1. Entrevista no grande grupo. Santa Maria (Rio Grande do Sul), 2012.

IGAND 12. Entrevista no grande grupo. Santa Maria (Rio Grande do Sul), 2012.

IGAND 13. Entrevista no grande grupo. Santa Maria (Rio Grande do Sul), 2012.

IGAND5. Entrevista no grande grupo. Santa Maria (Rio Grande do Sul), 2013.

IGAND 1. Entrevista no grande grupo. Santa Maria (Rio Grande do Sul), 2013.

IGAND2. Entrevista no grande grupo. Santa Maria (Rio Grande do Sul), 2013.

IGAND4. Entrevista no grande grupo. Santa Maria (Rio Grande do Sul), 2013.

IGAND5. Entrevista no grande grupo. Santa Maria (Rio Grande do Sul), 2013.

IGAND8. Entrevista no grande grupo. Santa Maria (Rio Grande do Sul), 2013.

IGAND9. Entrevista no grande grupo. Santa Maria (Rio Grande do Sul), 2013.

IGAND 14. Entrevista no grande grupo. Santa Maria (Rio Grande do Sul), 2013.

HABERMAS, Jürgen. Pensamento pós-metafísico: estudos filosóficos. Tradução de: Flávio Breno Siebenichler. Rio de Janeiro: Tempo Brasileiro, 1990.

HABERMAS, Jürgen. Teoria da ação comunicativa I: racionalidade da ação e racionalização social. Tradução Paulo Asthor Soethe e Flávio Beno Siebeneichler. São Paulo: Martins Fontes, $2012 \mathrm{a}$.

HABERMAS, Jürgen. Teoria da ação comunicativa II: sobre a crítica da razão funcionalista. Tradução Paulo Asthor Soethe e Flávio Beno Siebeneichler. São Paulo: Martins Fontes, $2012 \mathrm{~b}$. 
HERMANN, Nadja. Os alcances pedagógicos da crítica habermasiana à filosofia da consciência. In: DALBOSCO, Cláudio Almir; TROMBETTA, Gerson Luis; LONGHI, Solange Maria (org.). Sobre filosofia e educação: subjetividade e intersubjetividade na fundamentação da práxis pedagógica. Passo Fundo: Editora Universidade de Passo Fundo, 2004.

Profa. Dra. Denize da Silveira Foletto Universidade Franciscana (Brasil) Programa de Pós-Graduação em Ensino de Humanidade e Linguagens Grupo de Pesquisa Trajetórias de Formação - GTFORMA/CNPq Orcid id: https: / / orcid.org/0000-0002-38 10-8362 E-mail: denizefoletto@gmail.com

Profa. Dra. Sílvia Maria de Aguiar Isaia Universidade Federal de Santa Maria (Brasil) Programa de Pós-Graduação em Ensino de Ciências e Matemática Grupo de Pesquisa Trajetórias de Formação - GTFORMA/CNPq

Orcid id: http:/ / orcid.org/0000-0002-9987-793 1

E-mail: silviamariaisaia@gmail.com

Recebido 3 abr. 2020

Aceito 2 maio 2020 